persion), including the presentation of some new data by Kevin Riley (Prague) which intimated the important role of dispersion.

Finally, some more subtle points were also raised: e.g., the terminology of "halogen bonding" vs. "the halogen bond," and the proper representation of a halogen bond when drawing a molecular structure. Robin Rogers (Alabama, USA) closed the session with a presentation related to the journal Crystal Growth and Design, which will publish a special virtual issue featuring papers submitted by the speakers at this workshop (see http://pubs.acs.org/page/cgdefu/vi/ index.html). At the conclusion of the meeting, members of the IUPAC working group started working on a draft of the definition of halogen bonding.

From my perspective, this interactive and productive meeting brought together a diverse group of scientists, each with their own point of view on halogen bonding. This diversity is essential to establishing a consensus that supports a practical and accurate IUPAC definition of the halogen bond.

Cini www.halogenbonding.eu
David L. Bryce <dbryce@uottawa.ca> is an associate professor at the University of Ottawa (Canada). He obtained his B.Sc. (Honours) degree from Queen's University (1998). His Ph.D. thesis work (Dalhousie, 2002) was carried out in the group of Rod Wasylishen at Dalhousie University and the University of Alberta. This was followed by an NSERC postdoctoral fellowship with Ad Bax at the NIH (2003-2004). He currently serves as the chair of the Steering Committee for Canada's National Ultrahigh-Field NMR Facility for Solids. Research interests include solid-state NMR of quadrupolar and low-receptivity nuclides, quantum chemical calculations of NMR parameters, and biomolecular NMR. Recent activities include the development and application of solid-state NMR of the quadrupolar halogens, ${ }^{35 / 37} \mathrm{Cl},{ }^{79 / 8} \mathrm{Br}$, and ${ }^{12} \mathrm{I}$, which led to his current interest in halogen bonding and the potential for solid-state NMR to contribute to this area of research. Work with graduate student Cory Widdifield on ${ }^{127}$ I and ${ }^{185 / 187}$ Re solid-state NMR spectroscopy recently led to the observation of "higher-order quadrupolar effects." This necessitated the development and implementation of new simulation software by student Fred Perras, which treats quadrupolar interactions exactly rather than via second-order perturbation theory. The Bryce group has also recently initiated a research program in double-rotation NMR. A successful ongoing collaboration with J. Boisbouvier (IBS, Grenoble) led to the direct observation of $\mathrm{CH} / \pi$ interactions in proteins in 2010 .

Siiin http://mysite.science.uottawa.ca/dbryce

\section{Conducting Polymers}

\section{by Majda Zigon}

This 75th Prague Meeting on Macromolecules (PMM) was held 10-14 July 2011 at the Institute of Macromolecular Chemistry, Academy of Sciences of the Czech Republic (IMC) in Prague. It was devoted to conducting polymers, representing one of the most active and developing areas of polymer science. PMM conferences are well-known-the IMC has been organizing these international meetings every year since 1967.
The 75th PMM was organized by Jaroslav Stejskal and Miroslava Trchová under the auspices of the City of Prague, the vice-mayor Ivan Kabický, IUPAC, and the International Society of Electrochemistry. The conference has been approved as the official event of the International Year of Chemistry 2011. It attracted 124 participants from 37 countries and brought together both young and experienced researchers, as well as many students. At the opening ceremony, the attendees were welcomed by František Rypáček, director of the IMC, and Jaroslav Stejskal, co-organizer of the conference. The official IUPAC representative, Majda Žigon, from the National Institute of Chemistry in

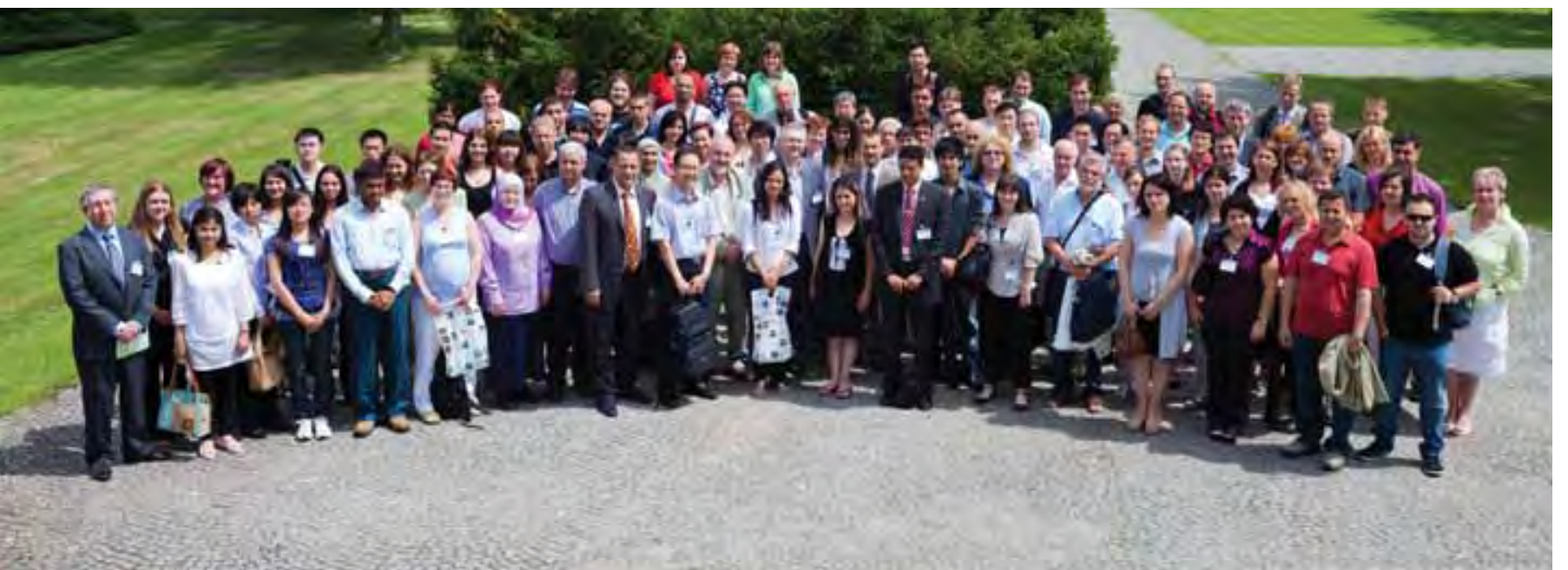


Ljubljana, Slovenia, outlined the activities of IUPAC in general and its Polymer Division in particular, as well as activities related to the International Year of Chemistry.

The conference highlighted areas such as the synthesis of conducting polymers and the preparation of their composites, their structural characterization, physical and chemical properties, modelling, and applications. The scientific program consisted of 7 invited lectures, 45 short contributed lectures, and 79 poster presentations. The invited lectures were of excellent quality and covered all aspects of conducting polymers. The first invited lecture was given by Adam Pron, France ("Low and High-Molecular-Weight Semiconductors for Organic Electronics: Synthetic Strategies, Characterization and Application to Organic Transistors). Other invited lectures were as follows:

- Gordana N. Ćirić-Marjanović, Serbia ("Computational Insights into the Mechanism of the Oxidative Polymerization of Arylamines")

- Mikhail A. Vorotyntsev, France ("Electrochemistry of Porphine-Based Electroactive Polymers")

- $\quad$ Andrey N. Aleshin, Russia ("Conducting PolymersInorganic Nanoparticles Composites for Organic Optoelectronics")

- Miroslava Trchová, Czech Republic ("PolyanilineSilver Composites")

- Jadranka Travas-Sejdić, New Zealand ("Two Applications of Scanning Ion Conductance Microscopy to Conducting Polymers: Electropolymerization and Ion Flux Measurement")

- Maria Omastová, Slovakia ("Polypyrrole, a Conducting Electroactive Polymer: From Past to Future").

The conference was held in a friendly and stimulating atmosphere. The participants followed the lectures with great interest, which was reflected in fruitful discussions, which extended throughout the day and culminated in afternoon poster presentations, accompanied by selected specialties of Czech cuisine and beer. The participants voted for the best poster presentations, which were awarded at the conference's closing ceremony. The winners were as follows:

- "Synthesis of Crystalline Polyaniline by Interfacial Polymerization" presented by Ahmed Mahmoud Youssef, Egypt

- "Controllable Optical, Electrical and Morphologic Properties of 3,4 ethylenedioxythiophen-based Electrocopolymerization Films" by Cheng Gu, China

- "Synthesis of Copolymers Used as Compatibilizers for Organic Solar Cells" by Sébastien-Jun Mougnier, France

- "Biocompatibility of Polyaniline" by Petr Humpolíček, Czech Republic.

Apart from the scientific work, the participants enjoyed a relaxed atmosphere in the evenings at the welcome reception, gala dinner, and during a visit to the Prague Old-Town Hall with the famous Astronomical Clock "Orloj," standing at the oldest and most important square of historical Prague.

The conference was a great success also thanks to the Organizing Committee, composed of Elena Konyushenko, Ivana Šeděnková, Patrycja Bober, Zuzana Rozlívková, and Milena Exnerová and the Conference Secretariat, represented by Daniela Illnerová and Marie Rodová. Special thanks go to the official sponsors named above, the conference associates, and to the industrial sponsors.

\section{www.imc.cas.cz/sympo/75pmm/}

\section{Chemical Safety and Security}

\section{by Leiv K. Sydnes}

As the International Year of Chemistry has unfolded, a steady flow of new organizations, societies, companies, and individuals have joined in and contributed to the celebration of the chemical sciences. This has increased the scope and perspective of the celebration, and over and over again we have seen how important chemistry is everywhere throughout the world. On 12-13 September 2011, the Organization for the Prohibition of Chemical Weapons, OPCW, became a celebrant as well, by organizing a Conference on
International Cooperation and Chemical Safety \& Security in The Hague, Netherlands.

The meeting was well attended, with some 350 participants on site and several hundred following the presentations through a webcast. The purpose of the conference was to promote the goals of the Chemical Weapons Convention (CWC) by highlighting the achievements of OPCW, but more importantly, by analyzing the challenges that lie ahead and discuss with important stakeholders how these challenges can be dealt with through coordinated actions and collaboration. All the most important players on the international scene were there, and those represent- 